\title{
Lambs immunized with an inactivated variant of Anaplasma phagocytophilum
}

\author{
Snorre Stuen ${ }^{*}$, Wenche Okstad ${ }^{1}$, Karin Artursson ${ }^{2}$, Basima Al-Khedery ${ }^{3}$, Anthony Barbet ${ }^{3}$ and Erik G Granquist ${ }^{4}$
}

\begin{abstract}
Background: Anaplasma phagocytophilum (formerly Ehrlichia phagocytophila) is an obligate intracellular bacterium causing the disease tick-borne fever (TBF) in domestic ruminants. An effective vaccine against the infection has been demanded for livestock by sheep farmers and veterinary practitioners for years.

Findings: In the present study, we immunized lambs with an inactivated suspension of $1 \times 10^{8}$ killed A. phagocytophilum organisms mixed with adjuvant (Montanide ISA 61VG; Seppic). Twelve 9-months-old lambs of the Norwegian White Sheep breed were used. A full two-dose series of immunization was given subcutaneously to six lambs with a 4 week interval between injections. One month after the last immunization, all lambs were challenged with the homologous viable variant of A. phagocytophilum. After challenge, all lambs showed clinical responses for several days, although the immunized lambs reacted with an anamnestic response, i.e. significant reduction in infection rate and a significantly higher antibody titer.
\end{abstract}

Conclusion: Immunization with inactivated A. phagocytophilum did not protect lambs TBF.

Keywords: Anaplasma phagocytophilum, Immunization, Sheep

\section{Findings}

Tick-borne fever (TBF) caused by the bacterium Anaplasma phagocytophilum (formerly Ehrlichia phagocytophila) is an endemic disease of sheep in tick (Ixodes ricinus) infested areas of Norway [1]. TBF has for decades been one of the main scourges for the sheep industry in the coastal areas of Norway. An effective vaccine against the infection has been demanded by sheep farmers and veterinary practitioners in Norway for years. However, there are currently no vaccines available against TBF. In endemic areas, prophylactic use of long-acting tetracycline, regular dipping or pour-on treatment with pyrethroids are used extensively [2]. However, there is a growing concern about the environmental safety and human health, increasing resistance in bacteria and their vectors related to antibiotics and chemical controls of ticks [3].

In the present study we investigated if an inactivated crude antigen based on inactivated bacteria from buffy

\footnotetext{
*Correspondence: snorre.stuen@nmbu.no

${ }^{1}$ Department of Production Animal Clinical Sciences, Norwegian

University of Life Sciences, Kyrkjevegen 332/334, 4325 Sandnes, Norway

Full list of author information is available at the end of the article
}

coat extracts could protect lambs upon challenge with live A. phagocytophilum.

Twelve unexposed 9-months-old lambs of the Norwegian White Sheep breed were used. All lambs belonged to the experimental sheep flock at the Department of Production Animal Clinical Sciences and were housed indoors during the trial. Two groups of lambs with mixed gender and equal distribution of mean live weight were established. The experimental study was ethically approved by the National Animal Research Authority (Norway).

The strain of A. phagocytophilum used originated from an infected lamb in a Norwegian sheep flock known to have problems with TBF. Based on partial sequencing of the $16 S$ rRNA gene, the variant of $A$. phagocytophilum was identical to GenBank accession number M73220. This variant has previously been evaluated in several infection studies $[4,5]$, and infected heparinised blood was stored at $-70^{\circ} \mathrm{C}$ with $10 \%$ dimethyl sulphoxide (DMSO). The batch of inoculum was used for antigen preparation and in the later infection challenges. 
In order to obtain a sufficient amount of bacterial inoculum, one unexposed lamb was infected intravenously with $2 \mathrm{ml}$ of a heparinized DMSO-stabilate of $A$. phagocytophilum. On the second day of fever (day 5 after inoculation), $300 \mathrm{ml} \mathrm{Na-citrated} \mathrm{blood} \mathrm{was} \mathrm{collected}$ from this lamb and the buffy coat was obtained at $4-6^{\circ} \mathrm{C}$, by centrifugation in a swing-bout bucket rotor (Heraeus Multifuge 3S-R, Termo Sci. Germany) at 2,500 $\times g$ for $30 \mathrm{~min}$. The isolated buffy coat was washed three times in $1 \times$ PBS at $1,500 \times g$ for $20 \mathrm{~min}$, and re-suspended in PBS after the last centrifugation. Quantification of the bacterial content in the buffy coat was determined by qPCR [6]. The buffy coat was frozen in $10 \mathrm{ml}$ aliquots at $-70^{\circ} \mathrm{C}$ for further analysis.

For antigen preparation, $10 \mathrm{ml}$ frozen buffy coat containing approximately $8 \times 10^{8}$ copies of $A$. phagocytophilum per ml was used. The material was inactivated using $0.3 \%$ formaldehyde [7] for $48 \mathrm{~h}$ at room temperature. Thereafter, the material was tested for lack of infectivity by intravenous inoculation into two naive lambs (data not shown).

The final preparation was made by mixing $1 \mathrm{ml}$ inactivated buffy coat and $1 \mathrm{ml}$ adjuvant (Montanide ISA 61 VG, Seppic). The antigen solution and the mineral oil adjuvant were mixed to water in oil emulsion using two syringes connected by a three way valve [7]. The final antigen dose contained approximately $1 \times 10^{8}$ inactivated $A$. phagocytophilum and was used immediately after preparation.

Six lambs were immunized subcutaneously twice (one month apart) with the inactivated crude antigens. One month after the last immunization, all lambs were infected intravenously with $2 \mathrm{ml}$ of the homologous viable batch of $A$. phagocytophilum with an approximate infection dose equal to $0.5 \times 10^{6}$ infected neutrophils per ml. A similar dose has earlier been used in other $A$. phagocytophilum infection studies $[1,4]$.

The lambs were clinically observed daily and the rectal temperature was measured, starting on the first day of immunization [5]. Blood samples (EDTA) were collected every third day for the first 14 days after each immunization and then daily during the fever period following the inoculation of infective blood. After the fever had subsided, blood samples were collected on a weekly basis. From these EDTA-blood samples haematological values including total and differential leucocyte counts were determined electronically (Technicon $\mathrm{H} 1^{\circledR}$, Miles Inc., USA) and blood smears were prepared and stained with May-Grünwald Giemsa [5].

In order to detect $A$. phagocytophilum infection EDTAblood samples were also analysed for Anaplasma-DNA by qPCR [6]. In addition, sera were collected every second week post each immunization and after challenge on days $0,7,14,21,28,42$, and 63 . Sera were analyzed using an indirect immunofluorescence antibody assay (IFA) to determine the antibody titers to an equine variant of $A$. phagocytophilum (formerly Ehrlichia equi) [8].

Statistical calculations were done using Statistix, version 4.0 (Analytical Software), and a two-sample $t$ test was used to compare clinical, haematological and serological variables. A $P$ value of $<0.05$ was considered significant.

No clinical signs or haematological changes were observed after immunization. However, all immunized lambs reacted with a firm palpable subcutaneous nodule without abscess formation at the site of inoculation, starting 3-4 days after each immunization which disappeared about 4 weeks post immunization.

After challenge, all lambs reacted with fever, bacteraemia, neutropenia and an antibody response typical of an A. phagocytophilum infection [4]. Although the result indicates a difference in the clinical and haematological variables, no significant differences were obtained (data not shown). However, there was a significant difference $(P<0.01)$ in level of bacteraemia (from days 4-9) and the antibody responses between immunized and control groups (Figs. 1, 2). After challenge, relapses of fever for 1-3 days occurred in two (33\%) and five (83\%) of the immunized and control lambs, respectively.

In the present study, no serologic response was observed after immunization. Lack of seroconversion observed in the immunized lambs could be due to low immunogenicity to the antigens used. However, the present serological test has earlier been used successfully when lambs were infected with the currently described variant of $A$. phagocytophilum [4]. Lack of detectable immune response could also be due to a low dose of antigen, masking of epitopes by formaldehyde treatment or the adjuvant used. Montanide ISA and formaldehyde

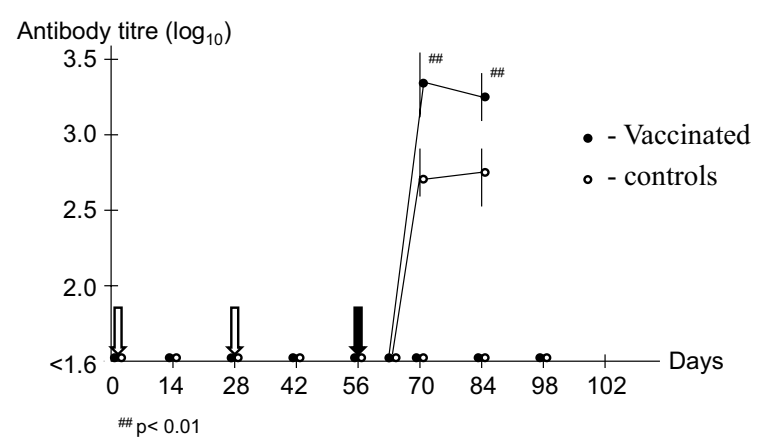

Fig. 1 Antibody titers in A. phagocytophilum-immunized (days 0 and 28) (white arrow) and control lambs. All lambs were challenged with live bacteria on day 56 (black arrow). A titer below $1.6(<1 / 40)$ was considered negative. 


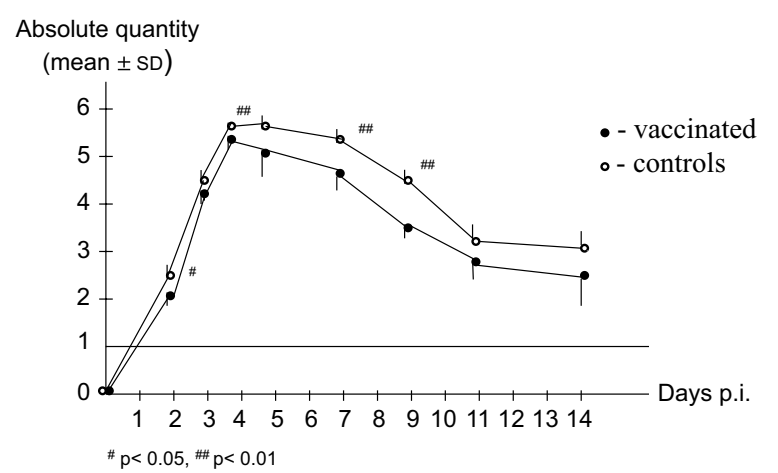

Fig. 2 A. phagocytophilum infection in vaccinated and control lambs post infection (quantitative PCR). The horizontal line is the threshold of bacteraemia (10 copies). The results are presented as logarithm transformed Cq readings $(X)$, calculated as $\log 10(1+X)$.

have earlier been included in vaccine preparations [7, 9], and a similar dose of antigen was used in a vaccination study with the related organism Ehrlichia ruminantium [10].

After challenge, there were no significant differences in temperature reaction or the differential leucocyte counts between the two groups of lambs, although significant differences $(P<0.01)$ were observed in infection levels and antibody responses. The increased number of fever relapses in the unimmunized lambs, indicates a more solid immunity to $A$. phagocytophilum after immunization [11]. These results indicate an anamnestic response, although too small to give protective immunity.

Immunity after experimental infection with a live variant of $A$. phagocytophilum varies from weeks to years [1]. A. phagocytophilum are obligate intracellular pathogens and cellular immunity is in general necessary for an effective immunity against such organisms [11]. However, antibodies to rickettsial infections have been shown to block the initial adhesion and penetration of the bacterium, enhance phagosome-lysosome fusion and phagocytosis followed by destruction of the organisms $[12,13]$.

An earlier observation indicates that specific antibodies could induce protection from Anaplasma infection. In one trial, mice were either vaccinated with a lysate of human variant of $A$. phagocytophilum (HGA-agent) or were given HGA-antisera directly from vaccinated mice. After challenge with the same variant, these mice were partially protected, indicating that antibodies are sufficient to protect substantially, but not fully against infection [14].

Crude preparation of the bacteria may expose mainly dominant antigens giving poor protection against disease due to irrelevant antigens derived either from the agent itself or from material used to produce it [15], although no detectable serological response was obtained after a similar immunization trial in lambs, using a purified cellcultured variant of $A$. phagocytophilum (Stuen, unpublished results).

In order to develop a successful vaccine, the challenge is to choose shared or subdominant antigens that are conserved amongst all strains of $A$. phagocytophilum and to produce these in sufficient quantity [16-18]. Genome sequencing of multiple strains [19] may be required to identify conserved antigens. Further research to develop sub-unitvaccines or live vaccine candidates should therefore focus on promoting the expression of sub-dominant surface proteins of $A$. phagocytophilum, as described in recent studies on the related organism $A$. marginale [20-22].

In conclusion, immunization with antigens based on the whole bacterium did not protect lambs from an $A$. phagocytophilum infection. After challenge, all lambs showed clinical responses for several days, although the immunized lambs had reduced levels of infection. Improved antigens are necessary in order to obtain protection from bacteraemia and clinical manifestation of tick-borne fever.

\section{Authors' contributions}

SS, BA, AB and EGG have designed the experimental study. SS performed the experimental study, carried out the statistical analysis and drafted the manuscript, WO performed the haematology, EGG carried out the molecular genetic analysis, and KA performed the serology. All authors read and approved the final manuscript.

\section{Author details}

${ }^{1}$ Department of Production Animal Clinical Sciences, Norwegian University of Life Sciences, Kyrkjevegen 332/334, 4325 Sandnes, Norway. ${ }^{2}$ Department of Bacteriology, National Veterinary Institute, SE-751 89 Uppsala, Sweden.

${ }^{3}$ Department of Infectious Diseases and Pathology, University of Florida, Gainesville, FL 32611, USA. ${ }^{4}$ Department of Production Animal Clinical Sciences, Norwegian University of Life Sciences, PO Box 8144, 0033 Oslo, Norway.

Acknowledgements

The study was funded by the Norwegian University of Life Science, Campus Høyland.

\section{Compliance with ethical guidelines}

\section{Competing interests}

The authors declare that they have no competing interests.

Received: 28 March 2015 Accepted: 6 June 2015

Published online: 25 July 2015

\section{References}

1. Stuen S (2003) Anaplasma phagocytophilum (formerly Ehrlichia phagocytophila) infection in sheep and wild ruminants in Norway. A study on clinical manifestation, distribution and persistence. Thesis, Dr. Philosophiae, Norwegian School of Veterinary Science, Oslo, p 124

2. Stuen S, Longbottom D (2010) Treatment and control of chlamydial and rickettsial infections in sheep and goats. Vet Clin North Am Food Anim Pract 27:213-233 
3. Samish M, Ginsberg H, Glazer I (2004) Biological control of ticks. Parasitology 129:S389-S403

4. Stuen S, Bergström K, Petrovec M, Van de Pol I, Schouls LM (2003) Differences in clinical manifestations and hematological and serological responses after experimental infection with genetic variants of Anaplasma phagocytophilum in sheep. Clin Diagn Lab Immunol 10:692-695

5. Stuen S, Grøva L, Granquist EG, Sandstedt K, Olesen I, Steinshamn H (2011) A comparative study of clinical manifestations, haematological and serological responses after experimental infection with Anaplasma phagocytophilum in two Norwegian sheep breeds. Acta Vet Scand 53:8

6. Granquist EG, Bårdsen K, Bergström K, Stuen S (2010) Variant- and individual dependent nature of persistent Anaplasma phagocytophilum infection. Acta Vet Scand 52:25

7. Tollersrud T, Zernichow L, Andersen SR, Kenny K, Lund A (2001) Staphylococcus aureus capsular polysaccharide type 5 conjugate and whole cell vaccines stimulate antibody responses in cattle. Vaccine 19:3896-3903

8. Stuen S, Bergström K (2001) Serological investigation of granulocytic Ehrlichia infection in sheep in Norway. Acta Vet Scand 42:331-338

9. Mahan SM, Smith GE, Kumbula D, Burridge MJ, Barbet AF (2001) Reduction in mortality from heartwater in cattle, sheep and goats exposed to field challenge using an inactivated vaccine. Vet Parasitol 97:295-308

10. Mahan SM, Kumbula D, Burridge MJ, Barbet AF (1998) The inactivated Cowdria ruminantium vaccine for heartwater protects against heterologous strains and against laboratory and field tick challenge. Vaccine 16:1203-1211

11. Tizard I (1992) Veterinary immunology, 4th edn. WB Saunders Company, Philadelphia

12. Kaylor PS, Crawford TB, McElwain TF, Palmer GH (1991) Passive transfer of antibody to Ehrlichia risticii protects mice from ehrlichiosis. Infect Immun 59:2058-2062

13. Messick JB, Rikihisa Y (1994) Inhibition of binding, entry, or intracellular proliferation of Ehrlichia risticii in P388D, cells by anti-E. risticii serum, immunoglobulin G, or Fab fragment. Infect Immun 62:3156-3161
14. Sun W, Ijdo JW, Telford SR III, Hodzic E, Zhang Y, Barthold SW et al (1997) Immunization against the agent of human granulocytic ehrlichiosis in a murine model. J Clin Invest 100:3014-3018

15. Mims C, Nash A, Stephen J (2001) Mimś pathogenesis of infectious disease, 5th edn. Academic Press, London, pp 392-415

16. Barbet AF, Lundgren AM, Alleman AR, Stuen S, Bjöersdorff A, Brown RN et al (2006) Structure of the expression site reveals global diversity in MSP2(P44) variants in Anaplasma phagocytophilum. Infect Immun 74:6429-6437

17. Ladbury GAF, Stuen S, Thomas R, Bown KJ, Woldehiwet Z, Granquist EG et al (2008) Dynamic transmission of numerous Anaplasma phagocytophilum genotypes among lambs in an infected sheep flock in an area of anaplasmosis endemicity. J Clin Microbiol 46:1686-1691

18. Scharf W, Schauer S, Freyburger F, Petrovec M, Schaarschmidt-Kiener D, Grzeszczuk A et al (2011) Distinct host species correlate with Anaplasma phagocytophilum ankA gene clusters. J Clin Microbiol 49:790-796

19. Dark MJ, Al-Kedery B, Barbet AF (2011) Multistrain genome analysis identifies candidate vaccine antigens of Anaplasma marginale. Vaccine 29:4923-4932

20. Agnes JT, Brayton KA, LaFollett M, Norimine J, Brown WC, Palmer GH (2011) Identification of Anaplasma marginale outer membrane protein antigens conserved between $A$. marginale sensu strict strains and the live A. marginale subsp. central vaccine. Infect Immun 79:1311-1318

21. Suarez CE, Noh S (2011) Emerging perspectives in the research of bovine babesiosis and anaplasmosis. Vet Parasitol 180:109-125

22. Barbet AF, Al-Khedery B, Stuen S, Granquist EG, Felsheim RF, Munderloh UG (2013) An emerging tick-borne disease of humans is caused by a restricted subset of strains with conserved genome structure. Pathogens 2:544-555

\section{Submit your next manuscript to BioMed Central and take full advantage of:}

- Convenient online submission

- Thorough peer review

- No space constraints or color figure charges

- Immediate publication on acceptance

- Inclusion in PubMed, CAS, Scopus and Google Scholar

- Research which is freely available for redistribution

Submit your manuscript at 